\title{
Evaluation of the Biomechanical Response, for the Comparison of Single vs Double Implants Replacing the Mandibular First Molar via a Three-dimensional Finite Element Analysis
}

\author{
Nikita Parasrampuria ${ }^{1}$, Nazish Baig ${ }^{2}$, Babita Yeshwante ${ }^{3}$, Vivek Jadhav ${ }^{4}$
}

\begin{abstract}
Aims and objectives: The study was conducted to evaluate the biomechanical response of the bone, for the comparison of single vs double implants replacing the mandibular first molar via a three-dimensional finite element analysis (FEA).

Materials and methods: Three-dimensional FEA model was generated to compare the induced displacements and stresses as a result of various loading conditions on a mandibular first molar crown supported by a regular 4.2-mm-diameter implant and two $3.5 \mathrm{~mm}$-diameter implants. For each implant design, the loading process $70 \mathrm{~N}$, on three locations (vertical to the long axis) was done and generated von Mises equivalent stress, and resultant displacements were recorded.

Results: For single implant design, the von Mises stress was found to be $173.61 \mathrm{MPa}$ at the distobuccal cusp tip, whereas for Double-implants (3.5 mm-implants), the maximum stress of $145.12 \mathrm{MPa}$ was found at the distobuccal cusp tip.

Conclusion: The use of double-diameter implants may be mechanically advantageous in restoring single molars, as they enhance the mechanical properties of the implant system through the increased surface area, stronger resistance to component fracture, increased abutment stability, and enhanced emergence profile.

Keywords: FEM, Implants, Mandibular first molar, Stress analysis.

International Journal of Prosthodontics and Restorative Dentistry (2021): 10.5005/jp-journals-10019-1302
\end{abstract}

\section{INTRODUCTION}

The ideal goal of modern dentistry is to restore the patient to normal contour, function, comfort, esthetics, speech, and health. What makes implant dentistry unique is the ability to achieve this ideal goal regardless of the atrophy, disease, or injury of the stomatognathic system. ${ }^{1}$ For years, patients were advised to place their desires aside and accept the limitations of a fixed partial denture. However, implant dentistry has remolded the available treatment option for the replacement of a posterior single missing tooth. Dental implant therapy based on the principle of osseointegration to replace the natural tooth has been widely accepted and well documented. ${ }^{2}$

Implant-supported restorations for fully and partially edentulous patients have exceedingly good long-term success rates. ${ }^{3,4}$

The suggested method of restoring a single implant-supported molar is to control the occlusion by reducing the force level and centering its action relative to the implant axis. ${ }^{4}$

Natural tooth size significantly increases in the molar region and proportionately the root surface area is almost double as compared to the other teeth in the dentition. Therefore, the clinicians face a unique biomechanical challenge. So to achieve the natural crown root ratio, implant diameter is often increased in the molar region for immediate loading, especially when the bone density is less or the masticatory forces are greater. ${ }^{5}$ Mechanical overload appears to be more of a problem with the implant-supported molar crown. Methods suggested improving biomechanics with an implant-supported single molar crown include the use of a
${ }^{1-4}$ Department of Prosthodontics and Crown and Bridge, Kusum Devi Sunder Lal Dugar Jain Dental College and Hospital, Kolkata, West Bengal, India

Corresponding Author: Nikita Parasrampuria, Department of Prosthodontics and Crown and Bridge, Kusum Devi Sunder Lal Dugar Jain Dental College and Hospital, Kolkata, West Bengal, India, Phone: +91 9836819592, e-mail: nikita.parasrampuria@gmail.com

How to cite this article: Parasrampuria N, Baig N, Yeshwante B, et al. Evaluation of the Biomechanical Response, for the Comparison of Single vs Double Implants Replacing the Mandibular First Molar via a Three-dimensional Finite Element Analysis. Int J Prosthodont Restor Dent 2021;11(1):27-32.

Source of support: Nil

Conflict of interest: None

wider-diameter implant and the use of two splinted implants to support a single crown. ${ }^{6}$ A recent in vitro model analysis by Seong et al. investigated implant strains associated with three different single-molar implant designs when subjected to various loading conditions. The investigators reported that the double implant design used in the study resisted loads better than the other two designs under most loading conditions. ${ }^{7}$ The complex geometry of the coupled bone-implant biomechanical system prevents the use of a closed-form approach for stress evaluation. Therefore, the behavior of endosteal dental implants can be investigated by using numerical techniques. Recently, the finite element method

(c) Jaypee Brothers Medical Publishers. 2021 Open Access This article is distributed under the terms of the Creative Commons Attribution 4.0 International License (https://creativecommons.org/licenses/by-nc/4.0/), which permits unrestricted use, distribution, and non-commercial reproduction in any medium, provided you give appropriate credit to the original author(s) and the source, provide a link to the Creative Commons license, and indicate if changes were made. The Creative Commons Public Domain Dedication waiver (http://creativecommons.org/publicdomain/zero/1.0/) applies to the data made available in this article, unless otherwise stated. 
has been widely applied to prosthetic dentistry to predict stress and strain distributions at peri-implant regions, investigating the influences of implant and prosthesis designs, the magnitude and direction of loads, and bone mechanical properties, as well as modeling different clinical scenarios. ${ }^{8}$ This study aims to evaluate the biomechanical response of the bone by the comparison of single vs double implants replacing the mandibular first molar via a three-dimensional finite element analysis (FEA).

\section{Aims and Objectives}

A three-dimensional FEA was conducted to compare the induced displacements and stresses as a result of various loading conditions on a mandibular first molar crown supported by a regular 4.2- $\mathrm{mm}-$ diameter implant and two $3.5 \mathrm{~mm}$-diameter implants.

\section{Materials and Methods}

A finite model of a section of mandibular bone with a missing first molar and an ADIN Touareg-S implant with an all-ceramic crown superstructure to replace a missing molar was generated in the study.

\section{Materials}

- A workstation computer with hardware Pentium four processor with 2 GB RAM.

- A 3D CAD Design software: software CATIA v5 R21.

- A FEA (or engineering simulation) software: ANSYS version 14.0.

- Manufacturer data of ADIN Implants with diameters $3.5 \mathrm{~mm}$, $4.2 \mathrm{~mm}$, and length of $10 \mathrm{~mm}$ each.

- An all-ceramic crown superstructure (mandibular first molar) was prepared on the model. The details of the external morphology of the crown being sourced from a standard textbook of Dental anatomy. This also was common for all finite element models.

\section{Methods}

The models were integrated into a single structure in the same software, such that the specified implant with the screw-retained straight abutment was vertically positioned in the bone block with the all-ceramic superstructure.

The 3-D model-Solid mathematical model of implant placed in bone (Fig. 1) was designed to simulate the three single molar implant designs for the comparison of the induced displacements and stresses as a result of various loading conditions on a mandibular first molar crown. The geometric properties of the two implant designs used for the analysis are elaborated in Table 1. The crown was supported by a

Design 1: Regular 4.2-mm diameter implant.

Design 2: Two $3.5 \mathrm{~mm}$ diameter implants.

The models which were generated were analyzed for a force magnitude of $70 \mathrm{~N}^{6}$ directed in the vertical ${ }^{6}$ direction. (This was kept constant throughout the study.)

Conversion to finite element model was done by applying material properties and meshing.

The 3D models were transferred to the ANSYS version 14.0 software for FEA, and Young's modulus and Poisson's ratio values of materials were inputted, the values being adopted from the literature, as given in Table 2 .

All materials were assumed to be linearly elastic, homogeneous, and isotropic. A state of optimal osseointegration was assumed, i.e., cortical and cancellous bone was assumed to be perfectly bonded to the implant. Meshed Models in the software were obtained (Figs 2 and 3 ).

This finite element model was divided into small elements. Each element was considered to be interconnected at several discrete points called nodes. Each model was meshed by elements defined

Table 1: Geometric properties of the three implant designs used for the analysis

\begin{tabular}{lll}
\hline Implant model & Diameter & Length \\
\hline 1st (single) & $4.2 \mathrm{~mm}$ & $10 \mathrm{~mm}$ \\
2nd (two implants) & $3.5 \mathrm{~mm}$ each & $10 \mathrm{~mm}$ \\
\hline
\end{tabular}

Table 2: The material properties

\begin{tabular}{lll}
\hline Material & $\begin{array}{l}\text { Young's modulus } \\
(\mathrm{GPa})\end{array}$ & Poisson's ratio \\
\hline $\begin{array}{l}\text { Titanium: implant, } \\
\text { abutment }\end{array}$ & 11 & 0.35 \\
Porcelain & 68.9 & \\
Mucosa & 10 & 0.28 \\
\hline
\end{tabular}

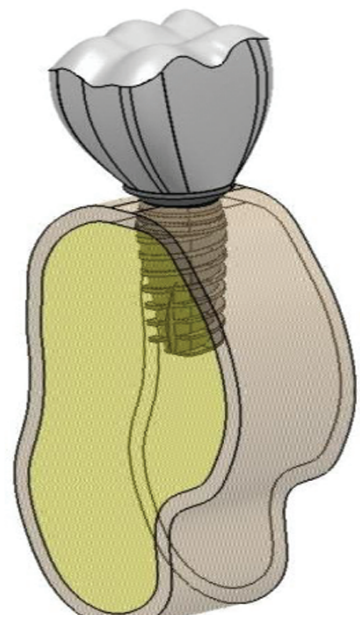

Fig. 1: The 3-D model-solid mathematical model of implant placed in the bone

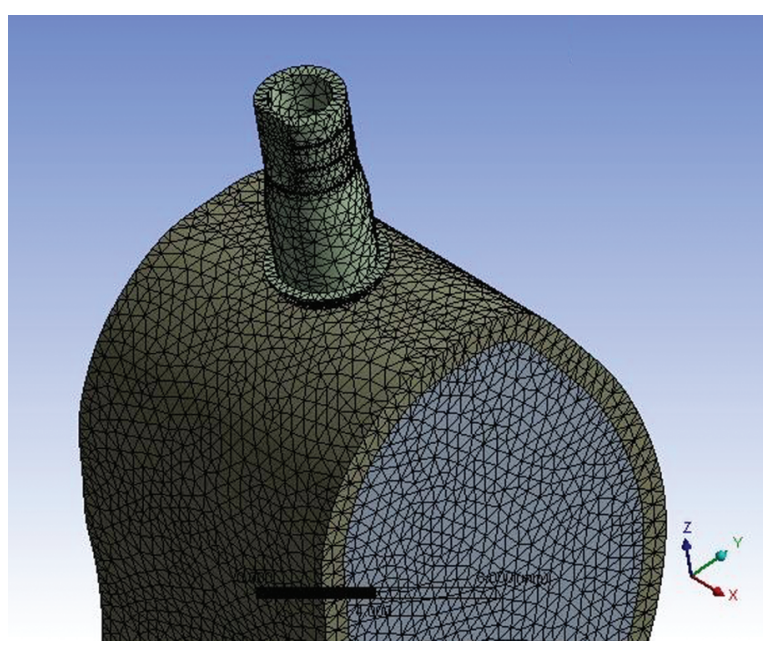

Fig. 2: Meshed models in the software for single implant 


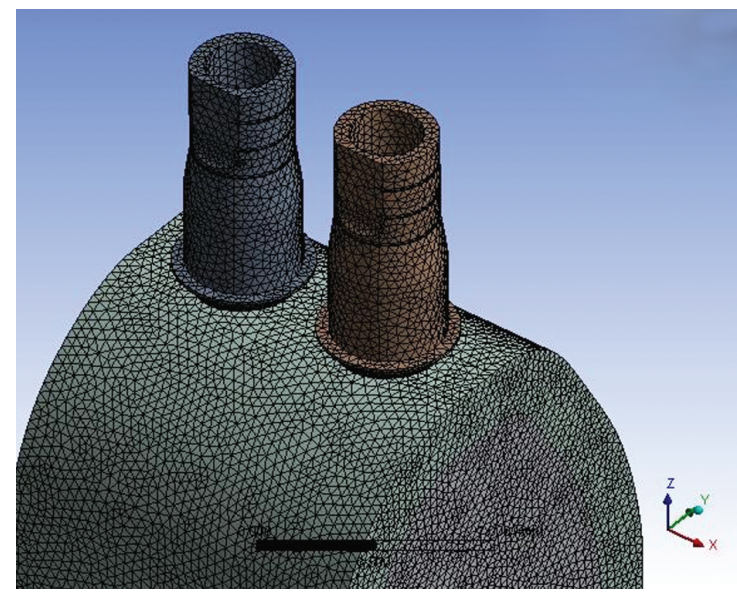

Fig. 3: Meshed models in the software for double implants

Table 3: Number of nodes and elements for each model

\begin{tabular}{llll}
\hline S.no. & Implant design & No. of nodes & No. of elements \\
\hline 1 & $\begin{array}{l}\text { Regular diam- } \\
\text { eter }-4.2 \mathrm{~mm}\end{array}$ & 294,811 & 178,352 \\
2 & $\begin{array}{l}\text { Double }-3.5 \\
\text { mm diameter }\end{array}$ & $2,041,278$ & $1,332,664$ \\
\hline
\end{tabular}

Table 4: von Mises stress distribution for the implants

\begin{tabular}{llll}
\hline & \multirow{2}{*}{ Point of } & \multicolumn{2}{c}{ von Mises stress (MPa) } \\
\cline { 3 - 4 } S. no. & application & Single $4.2 \mathrm{~mm}$ & Double, $3.5 \mathrm{~mm}$ \\
\hline A. & Central fossa & 162.24 & 127.73 \\
B. & $\begin{array}{l}\text { Distal marginal } \\
\text { ridge }\end{array}$ & 160.97 & 129.26 \\
C. & $\begin{array}{l}\text { Distobuccal } \\
\text { cusp tip }\end{array}$ & 173.61 & 145.12 \\
\hline
\end{tabular}

by 10 nodes and 3 degrees of freedom in tetrahedral bodies. The displacement of each of these nodes was calculated to determine the von Mises stresses throughout the structure. The number of nodes and elements for each model is given in Table 3.

The boundary conditions were established at the inferior surface of the models and a vertical intrusive force of $70 \mathrm{~N}$ was applied on the occlusal surface of all ceramic crown superstructure at three specified locations ${ }^{7}$ enumerated below:

Location A: Central fossa.

Location B: Buccolingual midpoint of the distal marginal ridge. Location C: Distobuccal cusp tip.

Values of von Mises equivalent stresses and resultant displacement throughout the models were computed using the FEA. Digital images were taken for each specimen to study the stress distribution pattern within all models-values and distribution of applied force $70 \mathrm{~N}$ on the designs (Fig. 4). Values for the most stressed elements of each variation were measured with the ANSYS software (version 14.0) at the specified locations.

\section{Results}

The results obtained from the FEA simulation showed the relationship between loads applied on the system, geometrical

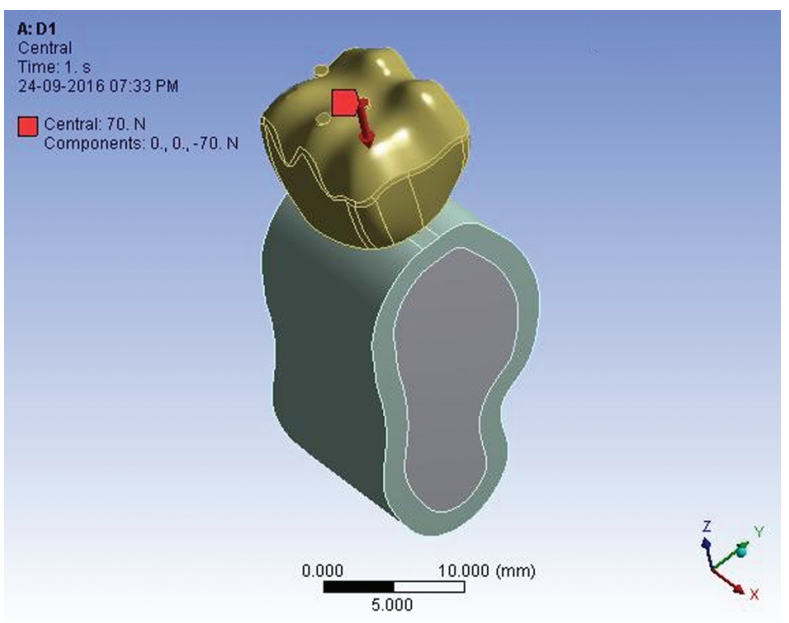

Fig. 4: Application $70 \mathrm{~N}$ force simulated on models

Table 5: Resultant displacement for the Implants

\begin{tabular}{llll}
\hline & \multirow{2}{*}{$\begin{array}{l}\text { Point of } \\
\text { S. no. }\end{array}$} & \multicolumn{2}{c}{ Resultant displacement $(\mu / \mathrm{m})$} \\
\cline { 3 - 4 } A. & Centration fossa & Single $4.2 \mathrm{~mm}$ & Double $3.5 \mathrm{~mm}$ \\
B. & $\begin{array}{l}\text { Distal marginal } \\
\text { ridge }\end{array}$ & 0.04 & 0.009 \\
C. & $\begin{array}{l}\text { Distobuccal } \\
\text { cusp tip }\end{array}$ & 0.039 & 0.019 \\
& & & 0.02 \\
\hline
\end{tabular}

characteristics of materials, joints, and strain. In materials science and engineering, the von Mises stress is used to predict the yielding of materials under any loading conditions from results of simple uniaxial tensile tests. Although formulated by Maxwell in 1865, it is generally attributed to Richard Edler von Mises (1913). The stresses were shown as different colors representing their magnitudes according to the legend given at the side of every figure.

Tables 4 and 5 contain the numerical findings pertaining to the force direction, force magnitude, the von Mises stress (Figs 5 and 6), and the resultant displacement. The results have been described under the designs of the implant-supported molar crown.

\section{Design 1: Regular Implant: 4.2-mm Implant}

For each implant design, the loading process $70 \mathrm{~N}$, on three locations (vertical to the long axis), generated von Mises equivalent stress and resultant displacements as follows, in the different bone qualities. The micro-movements and the stresses around the implant are:

\section{von Mises Stress}

The maximum stress of $173.61 \mathrm{MPa}$ at the distobuccal cusp tip (location C) and the least value of $160.97 \mathrm{MPa}$ at the distal marginal ridge (location $\mathrm{B}$ ) was observed (Table 4).

\section{Resultant Displacement}

The range of micro-movements was found to lie between 0.0175 and $0.04 \mu / \mathrm{m}$ other highest displacement of $0.04 \mu / \mathrm{m}$ was produced at the distal marginal ridge (location $\mathrm{B}$ ) (Table 5).

\section{Design 2: Double-implants (3.5 mm-Implants)}

For each implant design, the loading process $70 \mathrm{~N}$, on three locations (vertical to the long axis), generated von Mises equivalent stress and 


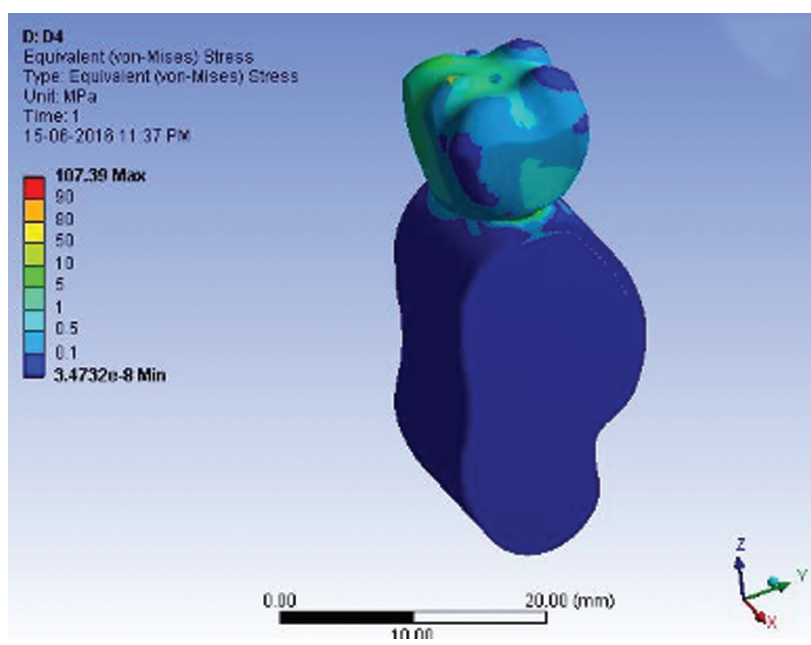

Figs $5 \mathrm{~A}$ and B: Von mises stress and displacements for designs 1

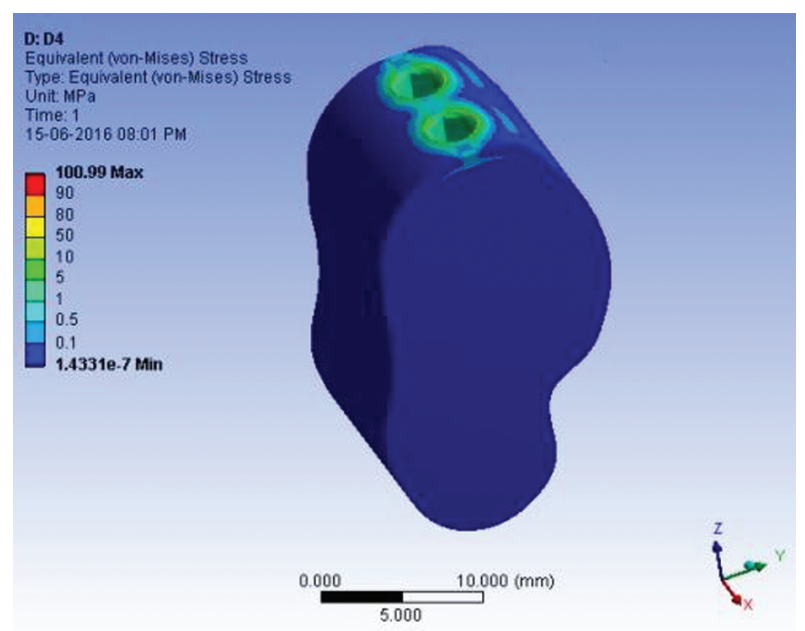

Fig. 6: Von mises stress and displacements for designs 2

resultant displacements as follows, in the different bone qualities. The micro-movements and the stresses around the implant are:

\section{von Mises Stress}

The maximum stress of $145.12 \mathrm{MPa}$ at the distobuccal cusp tip and the least value of $127.73 \mathrm{MPa}$ at the central fossa (location A) was observed (Table 4).

\section{Resultant Displacement}

The range of micro-movements was found to lie between 0.009 and $0.02 \mu / \mathrm{m}$. The highest displacement of $0.02 \mu / \mathrm{m}$ was produced at the distobuccal cusp tip (Table 5).

\section{Discussion}

During mastication, overstress around dental implants may cause bone resorption, which leads to infection in the peri-implant region and failure of oral rehabilitation. The way in which bone is loaded may influence its response. The results of cyclic loading into the bone differ from those of static loading. In the case of repetitive cyclic load application, stress microfractures in bone may occur and may induce osteoclastic activity to remove the damaged bone. So far, it is imperative to understand where the maximum

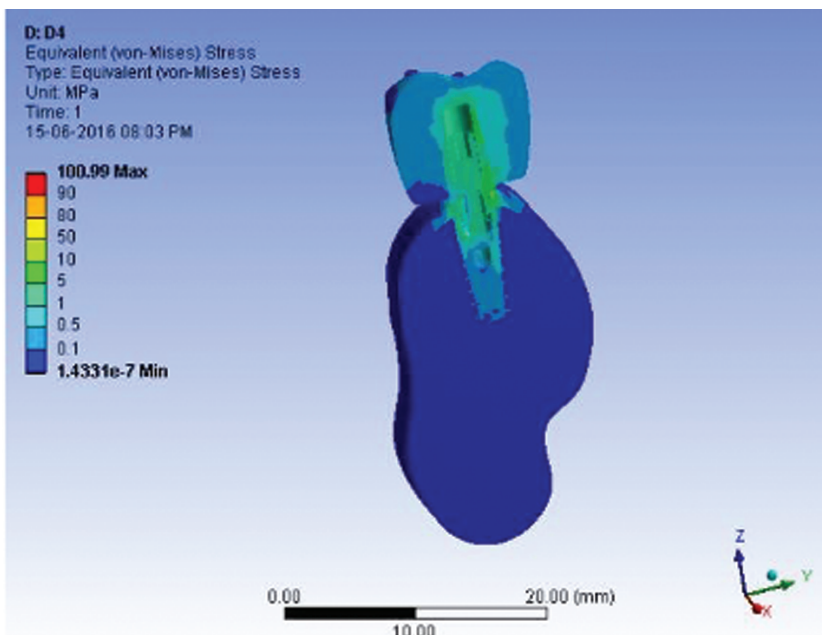

stresses occur during mastication around the implants to avoid these complications. ${ }^{9}$

Stresses in dental structures have been studied by various techniques, such as brittle coating analysis, strain gauges, holography, 2-dimensional (2D) and 3-dimensional (3D) photoelasticity, FEA, digital investigations, and other numerical methods. Finite element analysis is a popular numerical method in stress analysis. This method involves a series of computational procedures to calculate the stress and strain in each element, which performs a model solution. FEM circumvents many of the problems of material analysis by allowing one to calculate physical measurements of stress within a structure. ${ }^{3}$

Cibirka et al., in an in vitro simulated study, compared the force transmitted to the human bone by gold, porcelain, and resin occlusal surfaces and found no significant differences in the force absorption quotient of the occlusal surfaces among these three materials. ${ }^{10}$ Therefore, porcelain was used as the material for the crown superstructure. This study expressed the result (failure criteria) in maximum equivalent stresses (von Mises stresses). The reason for selecting von Mises criteria, which apparently results in a tensile type of normal stress, lies in the fact that the brittle materials (e.g., tooth, bone) fail primarily because of the tensile type of stress. ${ }^{11}$ The present study also measured the resultant displacement (which represents the absolute movement as a result of all the induced strains). ${ }^{6}$

The models simulated by the FEM analysis in the present study made a comparison between two different designs of the implant-supported molar crown. For the design variable, the two designs of the implant-supported crown experienced different values of stress and displacements. For the von Mises stress and resultant displacements, the double implant (design 2) performed better (strained less), deformed less than the regular diameter implant (design 1). This result was agreed well with the research observations of the following authors.

In the finite element study done by Geramy and Morgano, ${ }^{6}$ the micromotion was found to be better controlled by a wider diameter implant or by incorporation of two implants for a molar implantsupported crown. The reduction in mesiodistal displacement was especially pronounced with the double implant design and this design should be considered when the mesiodistal space for the artificial tooth is larger than average. These results observed by Geramy and Morgano ${ }^{6}$ were comparable to the present study. 
Balshi et al. ${ }^{12}$ stated that two implants for the restoration of a single molar can double the support capacity in the buccolingual direction. These results were comparable to the present FEA.

A radiographic comparison done by Bedi et al. ${ }^{13}$ demonstrated the superiority of the use of two standard-sized implants. Their research answered for the shortcomings associated with the wide diameter implants. These findings were analogous to the observations of the present study where the overall significant decrease for the double implant design indicates better clinical applicability. Petropoulos et al. ${ }^{14}$ in his clinical report identified the use of two implants as the most logical solution for the replacement of the missing mandibular molar, to overcome the masticatory overload in pronounced bruxers or clenchers.

In an in vitro study done by Seong et al., ${ }^{7}$ for the single-molar implant designs, an increase in implant number and diameter was found to effectively reduce the experimental implant abutment strains. He concluded that the regular diameter implant (design 1) experienced the largest implant abutment strains for all the tested conditions. The results of this study were comparable to the present FEA.

Bayrak et al. ${ }^{15}$ conducted a study to evaluate the effect of implant designs with different lengths and diameters on the stress distribution in abutments, implants, and cortical and trabecular bone of the edentulous mandible via three-dimensional FEA. Eight different finite models (cylindrical $3.5 \times 6$; cylindrical $3.5 \times$ 10.5; cylindrical $4.5 \times 6$; cylindrical $4.5 \times 10.5$; triple cylindrical 3.5 $\times 6$; triple cylindrical $3.5 \times 10.5$; triple cylindrical $4.5 \times 6$; and triple cylindrical $4.5 \times 10.5$ ) were created.

Within the limitations of this study, the triple cylindrical implants, with a new implant design, showed appropriate results in terms of an abutment, implant, and bone tissue stress. de Carvalho et al. ${ }^{16}$ conducted an in vitro study to test different planning options for replacing the mandibular first molar. Two small-diameter implants in an increased edentulous space show more optimized surface strain behavior than a single wide-diameter implant. However, a single $3.5-\mathrm{mm}$ implant also showed reduced strains in the restoration of the same edentulous space. Hence, no significant results were elicited.

Nevertheless, there are limitations to this study design as because of the natural variations in the constants for the mechanical properties of biologic tissue as well as their non-linear behavior, a FEM analysis cannot predict the behavior of biologic tissues and precisely cannot predict the behavior of the inert materials such as metal and porcelain. The vertical occlusal static loads used in the study do not produce the most challenging load transfer within the prosthesis or the surrounding bone. Greater differences are expected between different configurations when oblique loads are used, according to Becker and Becker. ${ }^{17}$

Ideally, two implants should be used to replace a single molar: however, a molar edentulous space is often bound by natural teeth, which results in insufficient mesiodistal bone width for placement of more than one ( $3.75 \mathrm{~mm}$ wide) implant. The study done by Sato et al. ${ }^{18,19}$ evaluated the biomechanical effects of double and wide implants for single molar replacement and concluded that forces for the double implants fluctuated from point to point. As FEM analysis does not consider the clinical complications, Balshi et al. ${ }^{12}$ reported higher marginal loss with double implants compared to single implants replacing a single molar. The biological factors, such as potential difficulty in maintenance of oral hygiene with double implant design, which resembles a molar with an advanced furcation invasion, were not taken into consideration for this analysis. The double implants present a greater surgical, prosthetic, and hygiene risk.

Therefore, within the limitations of this present FEA for the design variable, the higher number of implants provides the advantage of the greater seating surface and the greater outer surface area can reduce the stress levels on the implant components and bone-implant interface. Engineering principles suggest that the double implant arrangement provides better support for the artificial crown, and also this implant arrangement closely resembles the naturally occurring anatomic form of the roots of the mandibular molar.

\section{Conclusion}

The regular $4.2 \mathrm{~mm}$ diameter single implant produced the maximum micro-movements for the specified loading conditions in comparison to the $3.5 \mathrm{~mm}$ double implant. The use of double and wide diameter implants may be mechanically advantageous in restoring single molars as they enhance the mechanical properties of the implant system through the increased surface area, stronger resistance to component fracture, increased abutment stability, and enhanced emergence profile.

\section{References}

1. Tatum $\mathrm{OH}$. The Omni implant system. Proceedings of the Alabama Implant Congress, Birmingham, Ala, May 1988.

2. Adell R, Lekholm U, Rockier B, et al. A 15 year study of osseointegrated implants in the treatment of the edentulous jaw. Int J Oral Maxillofac Surg 1981;10(6):387-416. DOI: 10.1016/s0300-9785(81)80077-4.

3. van Steenberghe D, Lekholm U, Boienden C. The applicability of osseointegrated oral implants in the rehabilitation of partial edentulism: a prospective multicenter study of 558 fixtures. Int J Oral Maxillofac Implants 1990;5(3):272-281.

4. Thomas J, Wolfinger GJ. Two-implant-supported single molar replacement: interdental space requirements and comparison to alternative options. Int J Periodont Rest Dent 1997;17:427-435.

5. Terrence J, Griffin DMD, Wai S. The use of short, wide implants in posterior areas with reduced bone height: a retrospective investigation. J Prosthet Dent 2004;92(2):139-144. DOI: 10.1016/j. prosdent.2004.05.010.

6. Geramy A, Morgano SM. Finite element analysis of three designs of an implant-supported molar crown. J Prosthet Dent 2004;92(5):434-440. DOI: 10.1016/j.prosdent.2004.08.011.

7. Seong W-J, Korioth TW, Hodges JS. Experimentally induced abutment strains in three types of single-molar implant restorations. J Prosthet Dent 2000;84(3):318-326. DOI: 10.1067/mpr.2000.109124.

8. Baggi L, Cappelloni I, Girolamo MD, et al. Influence of implant diameter and length on stress distribution of osseointegrated implants related to crestal bone geometry: a three dimensional finite element analysis. J Prosthet Dent 2008;100(6):422-431. DOI: 10.1016/ S0022-3913(08)60259-0.

9. Assunção WG, Barão VAR, Gomes EA, et al. FEA in Dentistry: A Useful Tool to Investigate the Biomechanical Behavior of Implant Supported Prosthesis, Finite Element Analysis - From Biomedical Applications to Industrial Developments. Europe: Dr David Moratal (Ed.); 2012.

10. Sevimay M, Turhan F, Kilicxarslan MA, et al. Three-dimensional finite element analysis of the effect of different bone quality on stress distribution in an implant-supported crown. J Prosthet Dent 2005;93(3):227-234. DOI: 10.1016/j.prosdent.2004.12.019.

11. Srirekha A, Bashetty K. Infinite to finite: an overview of finite element analysis. Indian J Dent Res 2010;21(3):425-432. DOI: 10.4103/09709290.70813. 
12. Balshi TJ, Hernandez RE, Claudia M, et al. A Comparative study of one implant versus two replacing a single molar. Int J Oral Maxillofac Implants 1996;11(3):372-378.

13. Bedi RS, Verma P, Goel P, et al. Radiographic comparison of the two standardized implants with single wide diameter implant for replacement of one mandibular molar. Asian J Oral Health All Sci 2011;1:4-8.

14. Petropoulos VC, Wolfinger GJ, Balshi TJ. Complications of mandibular molar replacement with a single implant: a case report. J Can Dent Assoc 2004;70(4):238-242.

15. Bayrak A, Yaramanoğlu P, Kılıçarslan MA, et al. Biomechanical Comparison of a new triple cylindrical implant design and a conventional cylindrical implant design on the mandible by threedimensional finite element analysis. Int J Oral Maxillofac Implants 2020;35(2):257-264. DOI: 10.11607/jomi.7760.
16. de Carvalho EB, Herbst PE, Faria ACL, et al. Strain transfer behavior of different planning options for mandibular single-molar replacement. J Prosthet Dent 2018;119(2):250-256. DOI: 10.1016/j. prosdent.2017.03.017.

17. BeckerW, Becker BE. Replacement of maxillary and mandibular molars with single endosseous implant restorations: a retrospective study. $J$ Prosthet Dent 1995;74(1):51-55. DOI: 10.1016/s0022-3913(05)80229-x.

18. Sato $Y$, Shindoi N, Hosokawa R, et al. A biomechanical effect of wide implant placement and offset implant placement of three implants in the posterior partially edentulous region. J Oral Rehabil 2000;27(1):15-21. DOI: 10.1046/j.1365-2842.2000.00475.x.

19. Sato $Y$, Shindoi $N$, Hosokawa $R$, et al. Biomechanical effects of double or wide effects of double or wide implants for single molar replacement in the posterior mandibular region. J Oral Rehabil 2000;27(10):842-845. DOI: 10.1046/j.1365-2842.2000.00598.x. 